\title{
Normal Mycoflora on Spicess
}

\author{
Ankur Gupta ${ }^{1}$, Avnish Kumar ${ }^{2}$, Surabhi Mahajan ${ }^{1}$, BS Sharma ${ }^{3}$ and Monika Asthana ${ }^{2 *}$ \\ ${ }^{1}$ Department of Microbiology, Dr. B R Ambedkar University, India \\ ${ }^{2}$ Department of Biotechnology, Dr. B R Ambedkar University, India \\ ${ }^{3}$ Department of Environmental Studies, Dr. B R Ambedkar University, India
}

Submission: March 09, 2017; Published: May 30, 2017

"Corresponding author: Monika Asthanam, Department of Biotechnology, Dr. BR Ambedkar University, India, Email: monikasaxena@gmail.com

\begin{abstract}
Indian mothers use spices in kitchen and as medicinal tonics. Spices have also been reported worldwide for contamination due to fungal species which might be a risk of mycotoxins. Therefore, spices should be stored carefully and the growth of the naturally found toxic fungi should be inhibited. Fungal contamination of spices is a major impediment preventing India from export of more than $10 \%$ of its production. Normal mycoflora of frequently used spices in Indian kitchen has been reviewed herewith.
\end{abstract}

\section{Introduction}

Spices are readily used by us in food for aroma and also as medicinal remedy to sick family member. Our mothers would take small amount or spices and relevant herbs to make the recipe to soothe our pains. It is reported that the inadvisable higher dose of recipe made by plant part poses a definite risk if it contains toxic substances [1]. Spices also enhance the taste of food; deodorize living places, adding a pleasing scent around homes and other spaces. Additionally, they have also been proven to be essential raw materials for local enterprises in making soap, massage creams, body scrubs, ointments, and toothpastes. The anti-microbial activity of spices, as highlighted by inhibitory effects against bacteria and fungi, may alter the gut microbiota and influence various metabolic diseases. Many spices possess antioxidant and anti-inflammatory effects and could serve to prevent and mitigate various chronic diseases. Farmers who practice organic agriculture would extract and ferment the juice from harvested herbs so they may use it as an alternative to chemical sprays. Spices, herbs and dried vegetables seasonings are currently treated with ionizing radiation to eliminate microbial contamination. It was unambiguously confirmed that the treatment with ionizing energy is more effective against bacteria than the thermal treatment, and does not leave chemical residues in the food product [2-5]. Despite all the beneficial affects spices contain a normal mycoflora on their surface.

The Fungal pathogens of various food stuffs and agricultural commodities are a major problem. In the tropics and subtropics climatic conditions, agricultural and storage practices are conducive to fungal growth. The common fungal genera which are occurring frequently are Mucor, Rhizopus, Aspergillus, Penicillium, and Alternaria on Coriander and Cinnamon [6]. Prevalence of seed spice mycoflora depending upon the field and storage conditions. Fungal growth of stored spices is mainly influenced by Temperature and Relative Humidity.

India, despite being the largest producer of spices, there is great potential for increasing export of Indian spices.

As per international standards India lack higher proportion to be export due to

i. Lack of a number of improved seed varieties that suit different agro-climatic situations,

ii. Proper adoption of package practices

iii. Lack of control measures for diseases, pests and

iv. Post-harvest pathogens.

Pathogens adversely affect production and quality of spices. The seed-borne pathogens are one of the major causes of serious diseases in growing crops because of poor health and quality of seeds. Fungi are predominant contaminants of spices but most such myco populations are probably regarded as commensal residents on the plant that survived may be responsible for spoilage and degradation of spice quality by producing enzymes, mycotoxins and other secondary metabolites. An analysis of the composition of the fungi reveals that a great majority of fungal isolates belonging to Mitosporic fungi. Major population belongs to Zygomycetes, Ascomycetes and Mitosporic fungi. No Basidiomycetes were encountered till date. Alternaria 
alternata, Aspergillus flavus, Aspergillus niger, Aspergillus ustus, Cladosporium cladosporidies, Curvularia lunata, Fusarium oxysporum, Fusarium roseum, Helminthosporium tetramera, Trichoderma viride show maximum incidence on Agar plate and A. alternata, A. flavus, A. niger, A. ustus and H.tetramera have maximum incidence on Blotter plate by Sumanth et al. [7]; Kulshrestha et al [8]. Srivastava and Chandra [9] studied the mycobiota of 4 kind of spices (Coriandrum sativum, Cuminum cyminum, Foeniculum vulgare, Trigonella foenum-graecum) in India and reported that Aspergillus followed by Fusarium were the most frequent members. The percentage prevalence of these fungi evaluated. More than 53 fungi of different group recorded for toxin production.

Manjari et al. [10] assessed mycoflora of spices collected from local markets of Varnasi after 12 months of storage in metallic containers and isolated 39 and 24 fungal species from unsterilized and surface sterilized stored seeds, respectively. Fardos et al. [11] showed the prevalence and population density of the mycobiota of 50 samples belonging to 10 kinds of spices (Cuminum cyminum, Cinnamomum zeylanicum, Syzygium aromaticum, Piper nigrum, Elettaria cardamomum, Zingiber officinale, and Coriandrum sativum) which collected from different places in Jeddah Governorate were studied. Fifteen genera and thirty - one species of fungi in addition to one species variety were isolated and identified. The most common genera were Aspergillus, Penicillium and Fusarium. The natural occurrence of mycotoxins in those samples was also investigated. Aflatoxins $(12 \sim 40 \mu \mathrm{g} / \mathrm{kg})$ were detected in the extract of 5 samples of each of anise seeds and black pepper fruits; three samples of black cumin seeds and on sample only of each of peppermint and marjoram leaves out of 5 samples tested of each. Sterigmatocystin $(15 \sim 20 \mu \mathrm{g} / \mathrm{kg})$ was detected in some samples of red pepper, cumin and marjoram.

Microbiological analysis was carried out for the detection and enumeration of microorganisms. A total of 303 samples, representing different types of spices and medicinal plants were collected from random sources in Egypt. Also, samples were investigated for the mycological point of view and aflatoxins analysis was performed. Moreover, fungi were found in all of the collected samples. Aspergillus, Fusarium and Penicillium genera were more frequently detected than other genera (Alternaria, Absidia spp, Mucor spp, Rhizoctonia and Cladosporium spp.). The collected samples were found to be free of aflatoxins (B1, B2, G1 and G2). Importance of decontamination was suggested for spices and medicinal plants of high risk products [12].

Toma and Abdulla [13] studied microbial status of some crude herbal materials. A total of 16 samples, representing different types of spices and medicinal plants were collected from common market in the Erbil city, Iraq. Different fungal species were isolated and identified as Alternaria alternata, Aspergillus spp, Gliocladium spp, Hyaloden drondiddeus, Memmoniella spp, Penicillium spp, Rhizopus spp, Syncephalastrum spp, Cladosporium lignicolum and Ulocladium botrytis. The total number of isolated fungi from sixteen selected samples was Aspergillus spp. and Penicillium spp. while Stachybotrys sp., Syncephalastrum racemocum, Uocladium botrytis, Alternaria alternata, Cladosporium lignicolum and Gliocladium catenulatum were less frequently detected. Singh et al. [14] evaluate Coriandrum sativum, Cuminum cyminum, Foeniculum vulgare and Brassica seeds for storagee fungi from large number of samples from Agra India.

Studies investigating bacterial and/or fungal contamination of spices and herbs are reviewed. The high levels of microbial contamination in spices and herbs reported by many of the studies reviewed suggests a need for better control in all aspects of the production, processing and usage of these products to prevent potential food spoilage and food-borne illnesses due to contaminated spices and herbs [15]. Herbs and spices are amongst the most important targets to search for natural antimicrobial, antifungal and antioxidants from the safety point of view.

Elshafie et al. [16] studied 105 samples of 7 spices (Cuminum cyminum, Cinnamomum zeylanicum, Syzygium aromaticum, Piper nigrum, Elettaria cardamomum, Zingiber officinale, and Coriandrum sativum) purchased from five popular companies in the Sultanate of Oman. The spices were surveyed for the mycoflora and aflatoxins. Twenty fungal species were isolated in which Aspergillus flavus, A. niger. Penicillium, Rhizopus, and Syncephalastrum racemosum were the most dominant. When colony forming units per gm (cfu/gm) of fungi were compared, significant differences were found among spices and companies. Of the seven spices studied, clove was found to be the least contaminated, while Cuminum cyminum was the most contaminated. None of the 15 selected samples of the spices contaminated by $A$. flavus were found to contain aflatoxins. Nevertheless, nine isolates (45\%) of the twenty A. flavus strains screened for aflatoxins were aflatoxigenic. The moisture content of most of the spices was below the maximum standard limit.

El-Kady et al. [17] reported 38 genera and 81 species of fungi isolated from 120 samples of 24 kinds of spices collected from different places at Assiut Governorate, Egypt. Predominant genera were Aspergillus ( 25 species) and Penicillium ( 7 species) of which A. flavus, A. niger, A. ochraceus, A. fumigatus, A. flavusvar. columnaris, A. terreus, $P$. chrysogenum and P. corylophilum were the most commonly occurring.

Ath-Har et al. [18] studied the mycoflora of spices, including Piper nigrum, Coriandrum sativum, Capsicum frutescens, Cuminum cyminum, Foeniculum vulgare, Trigonella foenumgraecum and Brassica nigra, was investigated. A. flavus, A. niger, A. nidulans, A. sydowii, A. ochraceus, Penicillium and Rhizopus spp. were most frequently isolated from the spices. Fusarium moniliforme (Gibberella fujikuroi), F. solani, Curvularia lunata (Cochliobo luslunatus), Alternaria tenuis (A. alternate) and 
Drechslera (Setosphaeria) rostrata were also isolated from many samples. A total of 48 isolates of A. flavus were assessed for aflatoxin production. The clinical importance of fungal pathogens in spices There are more and more indications that primary liver carcinoma and other serious diseases may be induced by consuming food or using raw materials for food processing contaminated with fungi or mycotoxins. Aflatoxins, ochratoxin A and sterigmatocystin proved resistant to heat and have an ability to accumulate in the organism [19,20]. Even products stored at low temperatures are vulnerable to some fungi [21]. Fungal contamination of spices usually occurs when spices are not properly dried or when stored in a highly humid environment [22].

Tawfik and Allam [23] reported twenty fungus and ten bacterium isolates of microorganisms associated with Fusarium wilt disease infected Cuminum cyminum plants were obtained from samples collected from different locations of Assiut Governorate. On the basis of a preliminary antagonism test conducted in vitro, 3 fungal isolates (Trichoderma harzianum, T. humatum and T. viride) and one bacterial (Bacillus subtilis) isolate were screened. These antagonists were further screened by artificially infested potting soil bioassay including a commercial formulation (biocide 'Plant Guard') in addition to untreated seeds (positive control). The untreated seeds grown in the sterile soil free of the pathogen (negative control) were also used. No wilt symptoms were observed on the Cuminum cyminum plants raised from untreated seeds when grown in sterile soil (negative control) while untreated seeds grown in the infested soil (positive control) showed 90\% to 95\% infected plants. The plants grown under the latter treatment were significantly shorter with lesser weight than the former. Comparing with the positive control, all isolated antagonists and the biocide had a significantly lower percentage of infection and developed plants similar to the negative control concerning plant length and weight. The lowest percentage of infection was found in pre-sowing treatment with T. harzianum. However, there were no differences among the different bio-control seed treatments (locally isolated antagonists and the biocide) and the negative control treatment. We concluded that efficient bio-control agents might be developed via bioassay for microorganisms associated with local cumin cultures. This research is considered, therefore, a significant step toward finding an efficient environment friendly strategy for the management of Fusarium wilt disease in Cuminum cyminum.

A total of 120 different samples belonging to 24 kinds of spices collected from different places at Assiut Governorate (Egypt) were examined for the natural occurrence of mycotoxins by using TLC analysis of spice extracts revealed the presence of aflatoxins $(8-35 \mu \mathrm{g} / \mathrm{kg})$ in 16 samples of Pimpinella anisum, Piper nigrum, Carum carvi , Cuminum cyminum, Foeniculum vulgare, Mentha arvensis, Coriandrum sativum and Origanum marjorana), sterigmatocystin $(10-23 \mu \mathrm{g} / \mathrm{kg})$ in ten samples of Piper nigrum,
Carum carvi, Cuminum cyminum and Origanum marjorana and citrinin $(8-12 \mathrm{~g} / \mathrm{kg})$ in two samples of black cumin, while ochratoxin A and zearalenone could not be detected [17].

Vasanthi \& Bhat (2003) mycotoxins are produced by fungi, commonly known as mold. These toxins can develop during production, harvesting, or storage of grains, nuts, and other crops. Mycotoxins are among the most potent mutagenic and carcinogenic substances known. They pose chronic health risks: prolonged exposure through diet has been linked to cancer and kidney, liver, and immune-system disease. Because mycotoxins occur more frequently under tropical conditions and diets in many developing countries are more heavily concentrated in crops susceptible to mycotoxins, these chronic health risks are particularly prevalent in developing countries.

Most fungal diseases spread by infected seeds of coriander (C. sativum). A total of 23 species of parasitic and saprotrophic micro fungi were ascertained on the above ground parts of the coriander. Botrytis cinerea, Fusarium equiseti, Fusarium gibbosum, Passalora bupleuri, Phyllosticta cariandri, Phytophthora sp., Phomaapiicola, Puccinia petroselini (P. nitida) and Ramularia heraclei are the agents of plant fungal diseases. Thirty-one species of microfungi were isolated from not sterile Lithuanian coriander seeds. The most harmful pathogenic micro fungi agents of plant rots were isolated from sterile and nonsterile Lithuanian and introduced coriander seeds: Botrytis cinerea, Fusarium sambucinum [Gibberella pulicaris], Mortierel laisabellina (Umbelopsisisabellina), Sclerotinia sclerotiorum and Thielaviopsis basicola. Investigations on the germinating power of the Lithuanian and introduced coriander seeds revealed that the meteorological conditions, too early collection, drying and storage of seeds, as well as contamination with various microfungi, reduced the quality of seeds was studied by Stakvileviciene et al. [24].

Fungal products that are toxic to plants are called phytotoxins by plant pathologists, however, mistakenly the term phytotoxin can also refer to toxins made by plants. Fungi are major plant and insect pathogens, but they are not nearly as important as agents of disease in vertebrates, i.e., the number of medically important fungi is relatively low. Frank growth of fungi on animal hosts produces the diseases collectively called mycoses, while dietary, respiratory, dermal, and other exposures to toxic fungal metabolites produce the diseases collectively called mycotoxicoses. Mycoses range from merely annoying (e.g., athlete's foot) to life-threatening (e.g., invasive aspergillosis). The fungi that cause mycoses can be divided into two categories, primary pathogens (e.g., Coccidioides immitis and Histoplasma capsulatum) and opportunistic pathogens (e.g., Aspergillus fumigatus and Candida albicans). Primary pathogens affect otherwise healthy individuals with normal immune systems. Opportunistic pathogens produce illness by taking advantage of debilitated or immune compromised hosts. The majority of human mycoses are caused by opportunistic fungi. In plant 
pathology, many secondary metabolites produced by bacteria and fungi are pathogenicity or virulence factors, i.e., they play a role in causing or exacerbating the plant disease. The phytotoxins made by fungal pathogens of Cochliobolus (Helminthosporium) and Alternaria, for example, have well-established roles in disease development and several mycotoxins made by Fusarium species are important in plant pathogenesis.

The prevalence and population density of the mycobiota is also reported under natural occurrence of mycotoxins. Fifteen genera and thirty-one species of fungi in addition to one species variety were isolated and identified with most common genera Aspergillus, Penicillium and Fusarium. Aflatoxins $(12 \sim 40 \mu \mathrm{g} / \mathrm{kg})$ were detected in the extract of 5 samples of each of anise seeds and black pepper fruits; three samples of black cumin seeds and on sample only of each of peppermint and marjoram leaves out of 5 samples tested of each. Sterigmatocystin $(15 \sim 20 \mu \mathrm{g} / \mathrm{kg})$ was detected in some samples of red pepper, cumin and marjoram The inhibitory effects of 10 kinds of powdered spices were tested against 3 toxigenic isolates of fungi (Aspergillus flavus, $A$. versicolor and Penicillium citrinum). It inhibited the growth of the tested toxigenic fungi. Black pepper, peppermint, cardamom, cumin and marjoram completely inhibited aflatoxins production, while black pepper and cardamom also completely inhibited sterigmatocystin production [11]. Furthermore, Nigeria has experienced high recorded aflatoxin exposure levels in humans and has also reported the highest estimated number of cases of hepatocellular carcinoma (HCC-liver cancer) attributable to aflatoxins in the whole world. Fungi associated with common spices in Indian Kitchen.

\section{Coriandrum sativum}

Jain and Jain (1995) isolated 32 fungal species from 4 spice crop including coriander where Alternaria alternata was found dominant. Hashmi \& Ghaffar (1991) seed borne mycoflora of coriander from seed samples of 15 countries and isolated 24 fungal species belonging to 14 genera such as Alternaria alternata, Fusarium moniliforme, Phoma species, Fusarium semitectum, Fusarium solani, Fusarium equiseti, etc.

Pant (2011) collected and investigated coriandrum sativum seed samples from different Mandi's, shops, farms, farmers and seed division of Kota. A total of 23 fungal pathogens were isolated. Of these only six fungi showed presence in all the samples. Aspergillus niger showed maximum percentage relative density in seed. In another set of experiments metabolites of all the six fungi showing 100 percent frequency were tested for the effect of their metabolite on seed germination and seedling growth. All the six fungal metabolites affect seed germination and seedling growth with various degree of inhibition. Maximum inhibition in seed germination was observed in Rhizoctonia solani and maximum reduction in seedling growth was observed in Fusarium solani. Shrivastava \& Jain [25] analyzed seeds of Trachyspermum ammi, Piper nigrum, Coriandrum sativum and Cuminum cyminum collected from markets in Sagar, India, in the lab for the presence of fungal contaminants. A total of 26, 21, 20 and 25 species were recorded from each spice species, respectively, including Aspergillus flavus, A. niger, A. ochraceus, Penicillium spp., Rhizopus arrhizus, R. stolonifer and Syncephalastrum racemosum.

Several fungal diseases affect Coriandrum sativum. In Europe, Ramularia coriandri is of particular importance and resistance breeding of this fungus has been carried out in the former Soviet Union. Other fungal diseases are mildew (Erisyphe polygoni), and rust and leaf spots [26]. Mycotoxins continue to pose a health concern via human exposure to contaminated spices. Reports indicated average mold counts in the assorted peppers examined to range from 200 to 3400000 mold spores $\mathrm{g}^{-1}$ substrate. Of $49 \%$ of $A$. flavus isolates found to be toxigenic, $79 \%$ produced aflatoxin B1 (AFB1). Another investigation found AFB1 levels in Coriandrum sativum in excess of $75 \mathrm{ppb}$.

Coriandrum sativum seeds were found in a study on rats to have a significant hypolipidaemic effect, resulting in lowering of levels of total cholesterol and triglycerides, and increasing levels of high-density lipoprotein. This effect appeared to be caused by increasing synthesis of bile by the liver and increasing the breakdown of cholesterol into other compounds. Hedawoo \& Chakranarayan (2011) studied Trigonella foenumgraecum, Coriandrum sativum and Ammi visnaga are extensively used as spices and cultivated in Amravati region. Pathogens adversely affect the production and quality of spices. The seed-borne pathogens are one of the major causes of serious diseases in growing crops because of poor health and quality of seeds. Observed thirteen fungal species were Alternaria alternata, Aspergillus flavus, A. fumigatus, A. nidulans, A. niger, A. ochraceus, Cladosporium cladosporioidis, Curvularia lunata, Fusarium moniliforme, Mucor variance, Penicillium chrysogenum, Rhizopus nigricans and Syncephalastrum racemosum on above three spices seeds by Agar Plate Method (APM). Alternaria alternata, Aspergillus flavus, A. fumigatus, A. niger, A. ochraceus, Curvularia lunata, Penicillium chrysogenum and Rhizopus nigricans species were found most common on all the three spices seeds. Aspergillus niger counted the highest percentage of incidence i.e. $18.82 \%, 21.35 \%$ and $24.28 \%$ on the seeds of fenugreek, coriander and ammi respectively and lowest (4.33\%) of Penicillium chrysogenum on ammi seeds.

Fusarium oxysporum causes coriander wilt Srivastava, [25] and resistance screenings of this disease. Stem galls are caused by Protomyces macrosporus. Grain mould diseases caused by Helminthosporium spp., Fusarium spp., Curvularia spp. and Alternaria spp. Other fungal diseases are mildew (Erisyphe polygoni) and rust and leaf spots. The symptoms of these fungal diseases of the green plant are described by Palamarja \& Chotina 1953.

\section{Cuminum cyminum}

Garrido et al. (1988) evaluated the fungi contaminated of 33 different commercial spices and reported that only Myristica 
fragrans, Pimpinella anisum, A. dracunculus and Cuminum cyminum showed very low fungal contamination and in all cases Aspergillus flavus was found to be a predominant component of the mycobiota. Chohan et al. [27] studied samples of cumin seed from different locations of Balochistan for the detection of seed borne mycoflora. Twenty three species of fungi were isolated from cumin seed samples. Alternaria tenuis, Fusarium oxysporum, Fusarium equesti, Cladosporium, and Drechslera spicifer, were found predominating.

Rastogi (1993) found Alternaria burnsii to be a contaminant of black coloured seeds of cumin from 47 samples out of 105 samples from 16 districts of Rajasthan in blotter and agar plate technique.

Chand et al. (2000) investigated on the blotter and agar plate methods to study the seed borne fungi associated with 12 cumin seed samples collected from farmers in the Jobner region of Rajasthan, India. To test the pathogenicity of Alternaria spp., healthy surface sterilized seeds were rolled on a 7-day-old sporulating culture of Alternaria spp. and the inoculated seeds were sown in pots. In all, 8 fungi were isolated by the blotter and agar plate methods including A. alternata, Aspergillus niger, Aspergillus flavus, Curvularia lunata, Fusarium pallidoroseum, Aspergillus ochraceus, Rhizopus sp. and Drechslera rostrata (Setosphaeriarostrata). In the Alternaria spp. pathogenicity test, symptoms included tip burning, brown to black spots on leaves, stems and inflorescences, and blighting of most of the plant. Up to 19 more results found for "fungi associated with Cuminum cyminum.

Bhat et al. (1987) tested the microbial profile of Cuminum cyminum seeds and chilli powder sold in retail shops in the city of Bombay and reported that Aspergillus was the predominant genus in chilli powder samples. Also, they reported that no fungi were found in the cumin seed samples examined. Eighty-eight samples of black cumin seed were collected from commercial markets in Egypt and tested for seed-borne fungi. A total of 37 species of fungi belonging to 20 genera were identified. The pathogenicity of Fusarium oxysporum, F. solani, F. moniliforme and Verticillium sp. was studied on black cumin seeds and seedlings, using both seed and soil inoculation. A higher percentage of pre-emergence and post-emergence damping off developed from seed inoculation with each of the four fungi than from soil infestation. The transmission of Fusarium oxysporum, F. solani, F. moniliforme and Verticillium sp. from seed to mature plants of black cumin was also studied [28].

\section{Foeniculum vulgare}

In Egypt, (Moharram et al., 1989) isolated 25 species of Aspergillus in addition to 5 species varieties from Pimpinella anisum and Foeniculum vulgare seeds, of which A. niger, A. flavus, A. ochraceus and A. flavus var. colum-naris were the most prevalent on both Pimpinella anisum and Foeniculum vulgare seeds, but $A$. fumigatus and $A$. sydowii were more frequent on Pimpinella anisum than on Foeniculum vulgare. Kumar and Kumar
[29] has isolated Aspergillus flavus, A. niger, Rhizopus stolonifer, Cladosporium cladosporioides and Curvularia lunata (C. lunatus) from fennel (cultivars Fennel-6, Fennel-3, Mass-1, Local-1 and Local-2) seeds have caused seed infection and subsequently reduced the seed viability. Maximum reduction in seed viability (63.8\%) was recorded with $A$. flavus due to maximum seed infection (78.3\%), whereas R. stolonifer caused minimum seed infection $(52.6 \%)$ resulting in the lowest reduction in seed viability $(3.8 \%)$. Other test fungi produced the same effect, but in intermediate extent. Cultural filtrates of these fungi also produced adverse effect on seeds. Maximum retardation in seed germinability was recorded with culture filtrate of A. flavus followed by A. niger, Cladosporium cladosporiodes, Curvularia lunata and $R$. stolonifer.

Dwivedi etal. (2008) studied 127 seeds samples of Foeniculum vulgare belonging to 21 district of Rajasthan state revealed asymptomatic seeds(29-100\%), moderately discoloured seeds $(0.25-51.25 \%)$ and heavily discolored seeds $(0.25-19.75 \%)$ in 127,91 and 53 samples respectively in dry seed examinations. The discolorations include light brown-black spot to general browning of seeds. 76 seeds samples show microsclerotia and black tip of Cercospora foeniculi (0.25-48.25\%). 88 fungal species of 36 genera were recorded in incubation test of which, Aspergillus spp., Curvularia spp., Drechslera tetramera and Fusarium spp. were dominant and pathogenic. These caused loss in seed germination, seedling symptoms and mortality of seedling.

Herbs and spices are amongst the most important targets to search for natural antimicrobial, antifungal and antioxidants from the safety point of view. The investigations were designed to evaluate the potential of aqueous extract of fennel (Foeniculum vulgare Mill) against three soil borne fungi namely: Macrophomina phaseoli, Rhizocotina solani and Fusarium moniliforme. The test fungal species were grown in $100 \mathrm{ml}$ liquid extract medium containing $20 \mathrm{ml}$ each of $0,10,20,30,40,50$ and $60 \% \mathrm{w} / \mathrm{v}$ leaf extract of fennel and growth of fungi was monitored periodically after 5, 10 and 15 days of incubation. Concentrations of 10, 20 and $30 \%$ extracts of $F$. vulgare reduced the fungal biomass production in all tested pathogenic fungal species especially in initial growth stage. Fusaruim was found to be least influenced by the applied aqueous extracts. The higher concentrations of 40,50 and $60 \%$ aqueous extract of $F$. vulgare markedly enhanced fungal biomass production at all the harvest intervals was reported by Zahid et al. 2012 .

Hashem (2010) examined fifteen spices obtained from common markets for their mould profile. A total of 520 fungal isolates, representing 57 species, were recovered and identified from dried and ground spice samples on three different media using standard dilution plate method. The most heavily contaminated spice samples examined were observed in ginger in order of magnitude of 5325-6800 cfu/g. The most predominant fungal genera encountered were Aspergillus, Penicillium and Rhizopus. The emergence of Aspergillus, Penicillium and Rhizopus 
on the three different media greatly indicates the presence of these fungi as the dominant mycoflora of different spices.

The contamination with fungal species resulted from neutral extraneous contamination by dust following storage in humid conditions. Samples obtained from sumac encountered very rare colony counts indicating its antifungal properties. The present study attracts the attention to potential risk for mycotoxins contamination may be caused as a result of using these spices, especially in great quantities. Fungal identification from spices attracts the attention to potential risk for mycotoxins contamination and strongly recommends reduction in application of heavily contaminated spices and using some others like clove and sumac having antimicrobial properties. Whenever, improperly stored spices mycoflora get favorable environment for growth, they grow and their metabolic habits alter the quality and taste of the spices by secreting enzymes, toxins and other secondary metabolites.

\section{Summary and Conclusion}

The spoilage of spice quality and mycotoxin production mainly influenced by type of fungi, food composition and also handling and storage practices. It is strongly recommended to reduce the use of heavily contaminated spices in food processing and use of some others which having antimicrobial properties. More studies are required with an aim to investigate the benefits of spices and their normal mycoflora for relationships between diet and health, updated dietary recommendations, and the development of new therapies [30].

\section{References}

1. Asthana M, Kumar A (2014) Dose Response of Viola odorata on Meiotic \& Mitotic Chromosomes of Vicia faba. British Journal of Pharmaceutical Research 4(4): 520-530.

2. Tjaberg TB, Underdal B, Lunde G (1972) The effect of ionizing radiation on the microbial content and volatile constituents of spices. Journal of Applied Bacteriology 35: 473-478.

3. Loaharanu P (1994) Status and prospects of food irradiation Food Technology 52: 124-131.

4. Thayer DW, Josephson ES, Brynjolfsson A, Giddings GG (1996) Radiation pasteurization of food Council for Agricultural Science and technology- CSAT Ames Apr 7.

5. Olson D (1998) Irradiation of food. Food technology 52: 56-62.

6. Ramesh C, Jamadar S, Jayagoudar S (2013) Diversity of Fungi on Spices from Dharwad and Belgaum, Karnataka. A J B S 4(2) : 273-281.

7. Sumanth GT, Waghmare BM, Shinde SR (2010) Incidence of mycoflora from the seeds of Indian main spices. AJAR. 5(22) : 3122-3125.

8. Kulshrestha P, Singh C, Gupta A, Mahajan S, Sharma R et al. (2014) Mycoflora Associated With Spices International Journal of Current Microbiology and Applied sciences 5(3): 741-746.

9. Srivastava RK, Chandra S (1985). Studies on seed mycoflora of some spices in India: Qualitative and quantitative estimations. International Biodeterioration 21(1): 19-26.
10. Manjari K, Rai B, Jariwala S (1996) Seed mycoflora of some Indian spices of these effect on seed germination. J Ind Bot Soc 75: 221-224.

11. Fardos BM (2007) Spices Mycobiota and Mycotoxins Available in Saudi Arabia and Their Abilities to Inhibit Growth of Some Toxigenic Fungi Microbiology 35(2) : 47-53.

12. Abou Donia MA (2008) Microbiological quality and aflatoxinogenesis of Egyptian spices and medicinal plants.Global Veterinaria 2(4): 175181.

13. Toma FM, Abdulla NQF (2013) Isolation, Identification of Fungi from Spices and Medicinal Plants. Research Journal of Environment and Earth Science 5(3) : 131-138.

14. Singh B, Gitansh, Bhadauria S (2013) Prevalence of seed mycoflora from different seed of spices under field and storage conditions of Agra region.Asian Journal of Plant Science and Research 3(2): 93-98.

15. McKee LH (1995) Microbial contamination of spices and herbs: a review Lebensm Wiss Technol 28: 1-11.

16. Elshafie AE, AI-Rashdi TA, AI-Bahry SN, Bakheit CS (2002) Fungi and aflatoxins associated with spices in the Sultanate of Oman. Mycopathologia 155(3): 155-160

17. EI-Kady S, EI-Maraghy SM, Mostafa EM (1992).Contribution ofmesophilic fungi of different species in Egypt. Mycopathologic 120: 93-101.

18. Ath-Har MA, Prakash HS, Shetty HS (1988) Mycoflora of Indian spices with special reference to aflatoxin producing isolates of Aspergillus flavus IJM 28(12) : 125-127.

19. Galvano F, Ritieni A, Piva G, Pietri A (2005) Mycotoxins in the Human food chain. In: Duarate Diaz (Ed) Themycotoxin Blue Book. Nottingham University Press, England, pp. 187-225.

20. Jay J, Loessner M, Golden D (2005) In: Dennis R, Heldman (Ed) Modern Food Microbiology. Springer Science+ Business Media,Inc, New York, USA, pp. 709-726.

21. Durakovic S, Galic J, Pajnovic P (1989) Toksicniikancerogeni metabolite gljiva u namirnicama i krmivima. Hrana I ishrama 2: 71-100.

22. Dimic GR, Kocic-Tanackov SD, Tepic AN, Vujicic BL, Sumic ZM (2008) Mycopopulation of spices. BIBLID 39 : 1-9.

23. Tawfik AA and Allam ADA (2004). Improving cumin production under soil infestation with fusarium wilt pathogen: screening of biocontrol. AUBER 7(2): 35-45.

24. Stakvilevičienè S(2003) Microfungi on the overground part of coriander (Coriandrumsativum L.). Vagos 58 : 39-42.

25. Shrivastava A, Jain PC (1992) Seed mycoflora of some spices. Journal of Food Science and Technology (Mysore) 29(4) : 228-230.

26. Llewellyn GC, Mooney RL, Cheatle TH, Flannigan B (1992) Mycotoxin contamination of spices-An update. International Biodeterioration and Biodegradation. 29(2) : 111-121.

27. Chohan MA, Aqil T, Khan H (2001) Fungi associated with seed of cumin (Cuminumcyminum, L.) collected from different areas of Balochistan [Pakistan], Balochistan Journal of Agricultural Sciences 2(2): 42-44

28. Elwakil MA, Ghoneem KM (1999) Detection and location of seed-borne fungi of black cumin and their transmission in seedling. Pakistan Journal of Biological Sciences 2(2): 559-564.

29. Kumar B, Kumar S (2001) Seed mycoflora of fennel, their effect and control.Agri-Bio-Publishers, Hisar, India 17(1): 83-86.

30. Dawakhana H (2007) Coriander: Cure from the Kitchen. 
(C) This work is licensed under Creative Commons Attribution 4.0 License DOI: 10.19080/CTBEB.2017.05.555654
Your next submission with Juniper Publishers will reach you the below assets

- Quality Editorial service

- Swift Peer Review

- Reprints availability

- E-prints Service

- Manuscript Podcast for convenient understanding

- Global attainment for your research

- Manuscript accessibility in different formats

( Pdf, E-pub, Full Text, Audio)

- Unceasing customer service

Track the below URL for one-step submission https://juniperpublishers.com/online-submission.php 